in turn, is favorable for $\mathrm{H}^{+}$and $\mathrm{K}^{+}$secretion. It was also shown that gene mutation of $\mathrm{K}^{+}$channel causes Bartter's syndrome (9).

Gitelman's syndrome is a variant of Bartter's syndrome; it is known to accompany hypokalemia, metabolic alkalosis, and, in addition, hypocalciuria. This disorder is proven to link to the gene mutation of $\mathrm{Na}^{+}-\mathrm{Cl}^{-}$-cotransporter (10). The cause of hypokalemia and metabolic alkalosis is similar to Bartter's syndrome.

As mentioned above, with the accumulation of basic knowledge on renal physiology, the pathophysiology of not only the diseases in acid-base balance but also the other electrolyte disorders is being elucidated.

\section{References}

1) Alpern RJ, Rector FC. Renal acidification mechanisms. In "The Kidney", 5th edition, edited by Brenner BM, W.B. Saunders Company, Philadelphia, 1996.

2) Inaba M, Yawata A, Koshino I, et al. Defective anion transport and marked spherocytosis with membrane instability caused by hereditary total deficiency of red cell band 3 in cattle due to a nonsense mutation. $J$ Clin Invest 97: 1804, 1996.

3) Mune T, Rogerson FM, Nikkila H, Agarwal AK, White PC. Human hypertension caused by mutations in the kidney isozyme of $11 \beta$ - hydroxysteroid dehydrogenase. Nature Genetics 10: 394, 1995.

4) Venta PJ, Welty RJ, Johnson TM, Sly WS, Tashian RE. Carbonic anhydrase II deficiency syndrome in a Belgian family is caused by a point mutation at an invariant histidine residue (107His to Tyr): Complete structure of the normal human CA II gene. Am J Hum Genet 49: 1082, 1991.

5) Cohen EP, Bastani B, Cohen MR, Kolner S, Hemken P, Gluck SL. Absence of $\mathrm{H}^{+}$-ATPase in cortical collecting tubules of a patient with Sjögren's syndrome and distal renal tubular acidosis. J Am Soc Nephrol 3: 264, 1992.

6) Konishi K, Hayashi M, Saruta T. Renal tubular acidosis with autoantibody directed to renal collecting-duct cells. N Engl J Med 331: 1593, 1994 (letter).

7) Chang SS, Grunder S, Hanukoglu A, et al. Mutations in subunits of the epithelial sodium channel cause salt wasting with hyperkalaemic acidosis, pseudohypoaldosteronism type 1. Nat Genet 12: 248, 1996.

8) Simon DB, Karet FE, Hamdan JM, DiPietro A, Sanjad SA, Lifton RP. Bartter's syndrome, hypokalaemic alkalosis with hypercalciuria, is caused by mutations in the Na-K-2Cl cotransporter NKCC2. Nat Genet 13: 183, 1996.

9) Simon DB, Karet FE, Rodriguez-Soriano J, et al. Genetic heterogeneity of Bartter's syndrome revealed by mutations in the $\mathrm{K}^{+}$channel, ROMK. Nat Genet 14: 152, 1996.

10) Simon DB, Nelson-Williams C, Bia MJ, et al. Gitelman's Variant of Bartter's syndrome, inherited hypokalaemic alkalosis, is caused by mutations in the thiazide-sensitive $\mathrm{Na}-\mathrm{Cl}$ cotransporter. Nat Genet 12: 24, 1996.

\title{
5. A Functional Role for Endogenous Atrial Natriuretic Peptide in the Maintenance of Body Fluid Balance in Heart Failure
}

\author{
Masahiko Kinoshita and Atsuyuki WadA \\ The First Department of Internal Medicine, Shiga University of Medical Science, Ohtsu
}

Key words: heart failure, atrial natriuretic peptide, natriuretic peptide receptor antagonist, endothelin receptor antagonist, angiotensin II receptor antagonist

\section{Introduction}

Atrial natriuretic peptide (ANP) is secreted in response to atrial stretch and increases sodium excretion, inhibits the reninangiotensin-aldosterone, sympathetic activity and endothelin release. These vasoconstrictive neurohormones decrease renal blood flow, retain body fluid and aggravate heart failure. Recently, studies using a novel natriuretic peptide receptor antagonist have demonstrated a role for endogenous receptor ANP in cardiorenal homeostasis in normal and heart failure conditions (1-3). The importance of ANP, however, in the regulation of hormonal and renal function in heart failure remains controversial. Our previous studies have shown that the vasodilatory effects of ANP appear to be attenuated in advanced heart failure, suggesting the down-regulation of ANP receptors in vascular beds (4). Recent clinical studies have demonstrated that ANP infusion to patients with heart failure is effective, although the response is less sensitive with regard to the renal, hormonal and hemodynamic changes compared with normal control subjects (5-7).

The objective of the current study was to establish the functional roles of endogenous ANP in regulating renal and neurohumoral function by investigating ANP suppression, endothelin and angiotensin II suppression in a canine model with heart failure.

Reprint requests should be addressed to Dr. Masahiko Kinoshita, the First Department of Internal Medicine, Shiga University of Medical Science, 'Tsukinowa, Seta, Ohtsu 520-7129 
The effect of endogenous ANP in the setting of normal hemodynamic condition

Intravenous injection of ANP increases the glomerular filtration rate (GFR) primarily by decreasing afferent arteriolar resistance and increasing the resistance of efferent arterioles, and diminishes sodium reabsorption in the collecting duct (8). These effects of infused ANP are observed in physiological plasma concentration, as well as during pharmacological doses of ANP. The intrarenal infusion of HS-142-1, natriuretic peptide A receptor antagonist, alone decreased both absolute and fractional sodium excretion and renal cyclic GMP generation and increased distal tubular sodium reabsorption. These studies demonstrate that HS-142-1 markedly attenuates exogenous atrial natriuretic peptide-mediated natriuresis via the enhancement of distal tubular reabsorption and the blunting of increases in the glomerular filtration rate in the setting of normal cardiac function. Plasma renin activity, aldosterone and norepinephrine concentration did not increase after HS-142-1, suggesting that endogenous ANP does not influence basal endocrine secretion in the setting of physiological concentrations of ANP.

\section{The effect of endogenous ANP in the setting of mild heart failure}

We produced a canine model of heart failure by rapid ventricular pacing. The rapid ventricular pacing model (at 240270 beats per minute for 21 days) has been used extensively by our laboratory and by others to produce a model of severe heart failure. In the present study we adopted the pacing rate at 270 beats per minute for 10 days to produce a milder form of tachycardia-related cardiomyopathy. In this milder model of heart failure HS-142-1 produced decreases in renal cGMP generation, GFR and RPF, associated with decreases in urinary sodium excretion and fractional excretion of sodium. Fractional reabsorption of sodium at both the proximal and distal tubular levels increased. There was a significant increase in plasma renin activity associated with a trend toward an increase in plasma aldosterone concentration.

The findings of the current study support a pathophysiological role for ANP in mediating renal homeostasis in evolving heart failure.

\section{The effect of endogenous ANP in the setting of severe heart failure}

Endogenous ANP contributes to renal homeostasis and the suppression of the activation of the renin-angiotensin-aldosterone system. However, in severe heart failure endogenous ANP secretion increases more than in mild heart failure, which is associated with a depressed level of cGMP production despite the elevated level of ANP. This may be due to the downregulation of guanylate cyclase-coupled ANP receptors in vascular beds (9). HS-142-1 injection decreased urine volume and absolute sodium excretion, although there were no significant changes in GFR, RPF, or filtration fraction (FF). Therefore, endogenous ANP may have actually contributed to the excretion of sodium and water in severe heart failure without causing significant changes in GFR or RPF. Although ANP induces a preglomerular vasodilation and a post glomerular vasoconstriction with enhanced natriuresis in the normal hemodynamics, the vasodilative effect of endogenous ANP on the afferent arteriole seemed to be diminished, since there was no significant change in FF in the heart failure.

HS-142-1 increased plasma renin activity and aldosterone and plasma norepinephrine levels (Fig. 1). Therefore, endogenous ANP counteracted the vasoconstrictive and antinatriuretic hormones in heart failure. Exogenous ANP, infused intravenously, reportedly suppresses renin secretion, however, whether endogenous ANP has an inhibitory effect on renin release remains controversial. Although ANP-mediated renin inhibi-

\section{Endothelin-1}

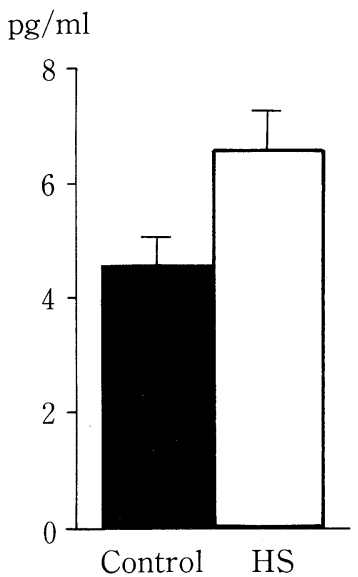

Renin activity

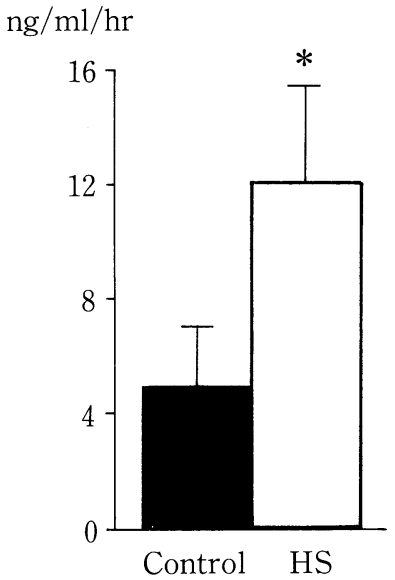

Aldosterone

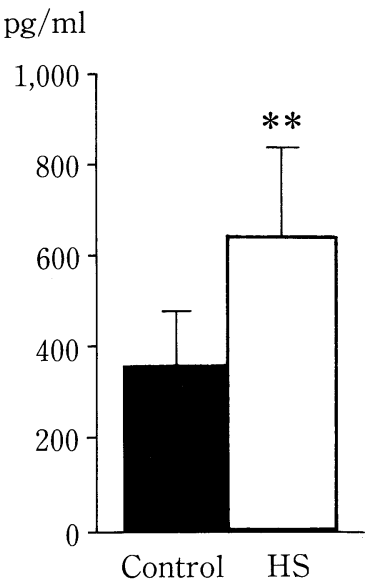

Figure 1. The effect of HS-142-1 on plasma renin activity, aldosterone and norepinephrine levels. HS-142-1 increased plasma renin activity, aldosterone and norepinephrine levels, indicating that endogenous ANP counteracted the vasoconstrictive and antinatriuretic hormones in heart failure. 
tion may involve a macula densa mechanism, the results of the present study do not allow us to distinguish between this and a direct receptor-mediated mechanism. A very high density of ANP receptor binding sites in the kidney was reported over the inner medulla, and the threshold ANP concentration for an increase in cGMP accumulation in the inner medullary collecting duct has been reported to be about 100 times highr than that in the glomeruli (9).

\section{The anti-heart failure effect of angiotensin II antagonist}

Angiotensin II increases glomerular efferent arteriolar tone and the filtration fraction, leading to increased solute reabsorption in the proximal tubule. In addition angiotensin II activates cGMP phosphodiesterase, resulting in the increased destruction of cGMP. Therefore, angiotensin II antagonist inhibits the action of phosphodiesterase, and elevates the action of ANP.

We administered angiotensin II antagonist (TCV-116) to dogs with pacing-induced heart failure for 2 weeks and compared it with a vehicle group. There was no significant difference in the pulmonary capillary wedge pressure or the plasma ANP between the TCV-116 treated groups and the vehicle group. The plasma cGMP levels, a second messenger of ANP, were two times higher in TCV-116 treated groups than in the vehicle group (10). This study indicates that angiotensin II antagonist upregulates guanylatecyclase-coupled ANP receptor in heart failure, resulting in the increased production of cGMP.

\section{The antiheart failure effect of selective endothelin antago-} nist

A recent report demonstrates that the endothelin concentra- tion in the left ventricle in experimental heart failure was elevated and that ET-A receptor antagonist improves survival (11). ET-A receptors mediate vasoconstriction, while ET-B receptors mediate vasorelaxation via the release of nitric oxide and prostacyclin. However, ET-B receptors also exist in smooth muscle and mediate vasoconstriction (12). Therefore, it may be valuable to see if both ET-A and ET-B antagonists are more effective when administered together rather than alone. We administered either ET-A receptor antagonist or ET-B receptor antagonist to dogs with heart failure induced by rapid ventricular pacing. The effects of both antagonists on hemodynamic, hormonal, and renal functions were studied. ET-A antagonist decreased cardiac pressures and the plasma ANP level and increased cardiac output. Urine flow rate and urinary sodium excretion were increased accompanied by an increase in both GFR and RPF. In contrast ET-B receptor antagonist increased cardiac pressures and decreased cardiac output, associated with a decrease in RPF, plasma renin activity and aldosterone concentration. These findings suggest that endogenous endothelin stimulates renin and aldosterone secretion via ET-B receptor. Recently Belloni et al also demonstrated that ET-B antagonist markedly reduces aldosterone secretion in dispersed zona glomerulosa cells (13).

\section{Conclusion}

Various neurohumoral factors such as ANP, BNP, renin, angiotensin II, aldosterone play important roles in modulating the sodium-water balance through cardiac and renal hemodynamics in heart failure. Endogenous ANP regulates sodium water reabsorption in the renal tubules, and also sup-

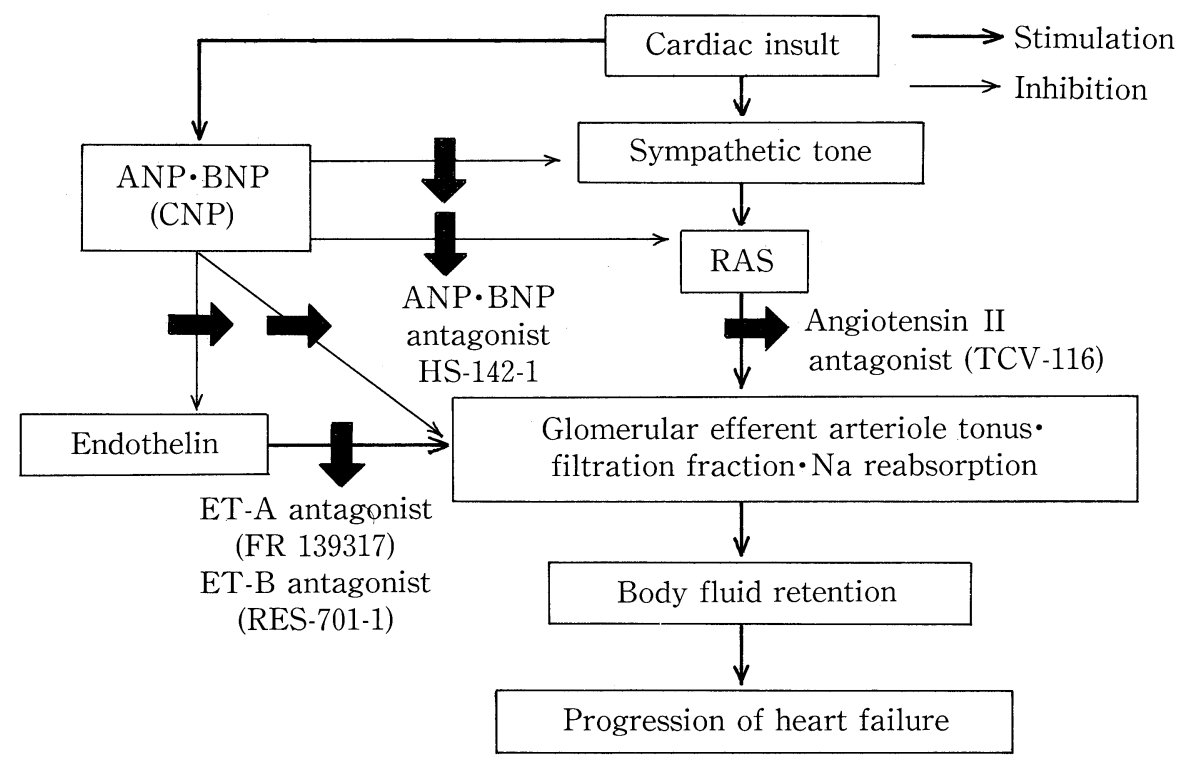

Figure 2. The relation between neurohumoral factors and the mechanism of body fluid retention in heart failure. Administration of various antagonist for each neurohumoral factor discloses the contribution of ANP, BNP, renin, angiotensin II, aldosterone and endothelin to modulating the sodium-water balance through cardiac and renal hemodynamics in heart failure. 


\section{KINOSHITA and WADA}

presses the releases of renin, angiotensin II, aldosterone, and endothelin (Fig. 2). Angiotensin II antagonist prevents the progression of heart failure by improving renal function. One of the mechanisms for the improvement of renal function is due to the up-regulation of ANP receptor, which leads to an increase in the production of cGMP at a given ANP concentration. ET-A antagonist has potential therapeutic benefits not only related to cardiac hemodynamics but also to renal sodiumwater regulation. ET-B antagonist possesses favorable effects of the suppression of the renin-angiotensin-aldosterone system in the treatment of heart failure.

\section{References}

1) Stevens TL, Wei CM, Aahrus LL, et al. Modulation of exogenous and endogenous atrial natriuretic peptide by a receptor inhibitor. Hypertension 23: 613, 1994

2) Wada A, Tsutamoto T, Matsuda Y, Kinoshita M. Cardiorenal and neurohumoral effects of endogenous atrial natriuretic peptide in dogs with severe congestive heart failure using a specific antagonist for guanylate cyclase-coupled receptors. Circulation 89: 2232, 1994.

3) Stevens TL, Burnett JC Jr, Kinoshita M, Matsuda Y, Redfield MM. A functional role for endogenous atrial natriuretic peptide in a canine model of early left ventricular dysfunction. J Clin Invest 95: 1101, 1995.

4) Tsutamoto T, Kanamori T, Morigami N, Sugimoto Y, Yamaoka O, Kinoshita M. Possibility of downregulation of atrial natriuretic peptide receptor coupled to guanylate cyclase in peripheral vascular beds of patients with chronic severe heart failure. Circulation 87: 70, 1993 (see comments).

5) Anand IS, Kalra GS, Ferrari R, Harris P, Poole-Wilson PA. Hemodynamic, hormonal, and renal effects of atrial natriuretic peptide in untreated congestive cardiac failure. Am Heart J 118: 500, 1989.

6) Eiskjaer H, Bagger JP, Danielsen H, et al. Attenuated renal excretory response to atrial natriuretic peptide in congestive heart failure in man. Int J Cardiol 33: 61, 1991.

7) Cody RJ, Atlas SA, Laragh JH, et al. Atrial natriuretic factor in normal subjects and heart failure patients. Plasma levels and renal, hormonal, and hemodynamic responses to peptide infusion. J Clin Invest 78: 1362, 1986.

8) Kim JK, Summer SN, Durr J, Schrier RW. Enzymatic and binding effects of atrial natriuretic factor in glomeruli and nephrons. Kidney Int 35: 799, 1989.

9) Nonoguchi H, Knepper MA, Manganiello VC. Effects of atrial natriuretic factor on cyclic guanosine monophosphate and cyclic adenosine monophosphate accumulation in microdissected nephron segments from rats. J Clin Invest 79: 500, 1987.

10) Maeda $Y$, Wada A, Tsutamoto T, Fukai D, Kinoshita M. Chronic effects of ANG II antagonist in heart failure: improvement of cGMP generation from ANP. Am J Physiol 272: H2139, 1997.

11) Sakai S, Miyauchi T, Kobayashi M, Yamaguchi I, Goto K, Sugishita Y. Inhibition of myocardial endothelin pathway improves long-term survival in heart failure. Nature 384: 353, 1996.

12) Sumner MJ, Cannon TR, Mundin JW, White DG, Watts IS. Endothelin ETA and ETB receptors mediate vascular smooth muscle contraction. $\mathrm{Br}$ J Pharmacol 107: 858, 1992.

13) Belloni AS, Rossi GP, Andreis PG, et al. Endothelin adrenocortical secretagogue effect is mediated by the $\mathrm{B}$ receptor in rats. Hypertension 27: $1153,1996$. 